\title{
Subahnale dan Rang-rang pembelajaran matematika SMP
}

\author{
Junaidi' ${ }^{1}$, Nourma Pramestie Wulandari ${ }^{1}$, Deni Hamdani ${ }^{1}$
}

${ }^{1}$ Pendidikan Matematika, FKIP, Universitas Mataram, Mataram

Junaidi88@unram.ac.id

Diterima:10-12-2021; Direvisi:30-12-2021; Dipublikasi:30-12-2021

\begin{abstract}
The purpose of this research is to find mathematical concepts in the cultural heritage of songket cloth and how to apply them as a medium for learning mathematics in junior high schools. The results of this study can be used as a reference for junior high school teachers to choose culture-based learning media related to student life, especially in Lombok. This research is an ethnomathematical research with the research method used is a qualitative research method with an ethnographic approach. The research was conducted in September, October, and November 2021 in Sukarara village, Lombok, West Nusa Tenggara. The subjects in this study were craft works in the form of songket cloth and songket weavers who were active in the village of Sukarara which consisted of three weavers. Data were collected by documentation, document observation, and interviews. The documents obtained were then analyzed related to the content of the mathematical concepts contained therein. The conclusion of this study is that the quality of mathematics learning can be improved by using the traditional songket subahnale cloth as a medium or learning aid. Some mathematical concepts that can be learned with songket subahnale as the medium are congruence, similarity, perimeter of flat shapes, area of flat shapes, folding symmetry, comparisons, pattern tracing. Songket fabrics that can be used as media are songket subahnale woven fabrics with geometric motifs such as diamond motifs, rang-rang motifs, and hexagons
\end{abstract}

Keywords: Songket, Subahnale, ethnomathematics

\begin{abstract}
Abstrak
Tujuan dari penelitian ini adalah untuk menemukan konsep-konsep matematika dalam warisan budaya kain songket dan bagaimana menerapkannya sebagai media pembelajaran matematika di Sekolah Menengah Pertama. Hasil penelitian ini dapat digunakan sebagai referensi bagi guru Sekolah Menengah Pertama untuk memilih media pembelajaran berbasis budaya yang berkaitan dengan kehidupan siswa khususnya di Lombok. Penelitian ini adalah penelitian etnomatematika dengan metode penelitian yang digunakan adalah metode penelitian kualitatif dengan pendekatan etnografi. Penelitian dilaksanakan pada bulan September, Oktober, dan November 2021 di desa Sukarara Lombok Nusa Tenggara Barat. Subjek dalam penelitian ini adalah karya kerajinan berupa kain songket dan penenun songket yang aktif di desa sukarara yang terdiri dari tiga orang penenun. Data dikumpulkan dengan dokumentasi, pengamatan dokumen, dan wawancara. Dokumen-dokumen yang didapatkan kemudian dianalisis terkait dengan muatan konsep matematika yang terkandung didalamnya. Kesimpulan penelitian ini adalah kualitas pembelajaran matematika dapat ditingkatkan dengan menggunakan kain tradisional songket subahnale sebagai media atau alat bantu pembelajaran. Beberapa konsep matematika yang dapat dipelajari dengan songket subahnale sebagai medianya adalah kekongrueanan, kesebangunan, keliling bangun datar, luas bangun datar, simetri lipat, perbandingan, penelusuran pola. Kain songket yang dapat dijadikan media adalah kain tenun songket subahnale motif geometri seperti motif ketupat, motif rang-rang, dan segi enam.
\end{abstract}

Kata Kunci: Songket, Subahnale, etnomatematika 


\section{PENDAHULUAN}

Nusa Tenggara Barat (NTB) khususnya Lombok merupakan salah satu daerah yang memiliki Kawasan Ekonomi Khusus (KEK) yang disebut dengan "KEK MANDALIKA". Destinasi wisata di daerah KEK MANDALIKA salah satunya adalah pantai Kuta. Selain itu KEK MANDALIKA juga memiliki Circuit balapan yang juga memberikan daya tarik tersendiri yang dimiliki daerah NTB khususnya Lombok. World Super Bike (WSBK) yang diselenggarakan di Lombok pada 19-21 November 2021 tentu merupakan ajang internasional yang akan mendatangkan wisatawan-wisatawan asing ke Lombok.

Acara WSBK tentu disambut dengan meriah dengan mengadakan pameran-pameran budaya khas NTB yang ada di Lombok. Budaya-budaya tradisional NTB hingga produkproduk local NTB dipamerkan untuk diperkenalkan kepada wisatawan asing di Lombok. Salah satu produk warisan budaya yang dipromosikan adalah kain tradisional "songket". Berbagai jenis kain songket dipromosikan pada acara WSBK Mandalika.

Promosi wisata yang diadakan pemerintah dalam rangka melestarikan budaya lokal NTB khususnya kain songket tentu patut diapresiasi. Akan tetapi beberapa kenyataan yang ditemukan adalah generasi-generasi muda Lombok NTB masih banyak yang tidak mengenal dan bahkan tidak tahu tentang warisan budayanya sendiri khususnya kain songket. Hasil survey yang dilakukan kepada anak-anak SMP tahun 2021 diperoleh bahwa dari 10 siswa yang ditanyakan hanya satu orang yang tahu tentang kain songket. Hal tersebut tentu akan menjadi hal yang sangat disayangkan karena wisatawan asing atau orang luar negeri akan lebih mengenal warisan budaya khusunya di Lombok NTB dibandingkan dengan generasi atau masyarakat Lombok sendiri. Selain itu kurikulum pendidikan di Sekolah Menengah Pertama di Lombok tidak mengintegrasikan budaya dalam pembelajaran. Tidak ditemukan buku referensi yang memuat budaya-budaya local atau warisan budaya sebagai bagian dari konten pembelajaran. Selain itu warisan budaya kain songket saat ini telah mengalami degradasi nilai, masyarakat Lombok lebih bangga menggunakan produk-produk luar dibandingkan dengan dengan warisan budaya sendiri (Netrawati et al., 2019). pendidikan seharusnya dapat menjadi wahana menyebaran budaya dan pelestraian budaya sehingga sekolah harus mengambil peranannya dalam pelestarian warisan budaya.

Pembelajaran matematika berbasis budaya atau etnomatematika perlu untuk di kembangkan sehingga minat dan pengetahuan siswa tentang warisan budaya dapat dipertahankan. Selain itu pemahaman peserta didik terhadap warisan budaya yang secara tidak langsung menumbuhkan karakter cinta tanah air (laurens, 2017). Pembelajaran matematika berbasis etnomatematika dapat digunakan untuk meningkatkan kualitas pembelajaran karena pembelajaran matematika berbasis etnomatematika terbukti efektif dalam meningkatkan kemampuan pemahaman matematika siswa (Sarwoedi et al., 2018). Pembelajaran matematika bernuansa 
etnomatematika mampu menurunkan kecemasan siswa (Ulya \& Rahayu, 2017). Pembelajaran matematika dikaitkan dengan kehidupan sehari-hari siswa sebagai kegiatan belajar perlu ditingkatkan. Hal tersebut dapat dilakukan karena konsep matematika yang dapat dieksplorasi dalam budaya (laurens, 2017). Guru mengajak siswa belajar matematika dari konteks-konteks nyata yaitu kehidupan disekitar siswa. Guru mengajak siswa belajar matematika dengan pengalaman konkrit.

Dalam rangka meningkatkan muatan budaya dalam pembelajaran matematika maka perlu dilakukan kajian-kajian etnomatematika yang termuat dalam warisan-warisan budaya khususnya kain songket yang ada di Lombok sebagai bahan belajar siswa. Oleh karena itu perlu dikaji tentang etnomatematika kain tradisional khas Lombok "songket". Hasil kajian dapat dijadikan sebagai bahan ajar dalam pembelajaran matematika. Bahan Ajar Berbasis Etnomatematika yang dikembangkan efektif untuk meningkatkan pemahaman belajar siswa (Muhammad \& Novitasari, 2020). penerapan pendekatan pembelajaran berbasis etnomatematika dapat meningkatkan minat belajar siswa dan aspek kognitif siswa serta interaksi antar siswa dapat terbangun dengan penerapan pembelajaran berbasis etnomatematika (Khairida, 2019)

Kain songket merupakan kain yang berhubungan dengan dunia spiritual, sakral, dan memiliki nilai-nilai estetika yang tinggi dan bagian dari ritual adat istiadat suku Sasak. Matematika dapat diajarkan melalui budaya (Kencanawaty \& Irawan, 2017). Motif atau Bahasa Sasaknya di sebut dengan Reragian yang cendrung dibuat berbentuk pola geometris sehingga hasil tenunan kain songket berbentuk garis-garis memanjang, persegi panjang, persegi empat, dan segi tiga perpaduan semua unsur-unsur geometris (Efendi et al., 2014). Pembelajaran geometri berbasis etnomatematika dapat meningkatkan kemampuan berpikir kritis siswa (Suhartini \& Martyanti, 2017). Dengan adanya unsur-unsur geometri dalam motif atau reragian kain songket maka perlu juga dikaji lebih dalam tentang konsep-konsep lain dalam kain songket yang dapat dijadikan sebagai media dalam pembelajaran matematika karena banyak konsep matematika yang terkandung dalam kain-kain tenun songket (Panjaitan et al., 2021) sehingga dapat digunakan dalam meningkatkan kualitas pembelajaran matematika. Pembelajaran matematika berbasis etnomatematika juga dapat meningkatkan kemampuan komunikasi matematika siswa (Heryan \& Zamzaili, 2018).

Tujuan dari penelitian ini adalah untuk menemukan konsep-konsep matematika dalam warisan budaya kain songket dan bagaimana menerapkannya sebagai media pembelajaran matematika di Sekolah Menengah Pertama. Hasil penelitian ini dapat digunakan sebagai referensi bagi guru Sekolah Menengah Pertama untuk memilih media pembelajaran berbasis budaya yang berkaitan dengan kehidupan siswa khususnya di Lombok

\section{METODE PELAKSANAAN}

Metode penelitian yang digunakan adalah metode penelitian kualitatif dengan pendekatan etnografi. Penelitian dilaksanakan pada bulan September, Oktober, dan 
November 2021 di desa Sukarara Lombok Nusa Tenggara Barat. Subjek dalam penelitian ini adalah karya kerajinan berupa kain songket dan penenun songket yang aktif di desa sukarara yang terdiri dari tiga orang penenun. Data dikumpulkan dengan dokumentasi, pengamatan dokumen, dan wawancara. Dokumen-dokumen yang didapatkan kemudian dianalisis terkait dengan muatan konsep matematika yang terkandung didalamnya. Dokumen-dokumen yang dikumpulkan adalah foto-foto terkait dengan kain songket yang mengandung konsep-konsep geometri. Dokumen yang mengandung konsep geometri kemudian dianalisis untuk menemukan konsep apa saja yang dapat di terapkan dalam pembelajaran matematika dengan kain songket sebagai media pembelajaran. Wawancara digunakan untuk mengetahui nama motif dan ukuran-ukuran hasil tenun kain songket.

\section{HASIL DAN PEMBAHASAN}

Kain songket merupakan kerajinan tangan. Proses pembuatan kain songket disebut dengan "Nyensek" yang berarti nenun atau menenun. Selembar kain songket di tenun dalam waktu yang berbeda-beda tergantung kecekatan dari penenun. Paling cepat satu kain dapat diselesaikan dalam waktu tiga minggu atau 21 hari.

Kain songket dibedakan berdasarkan motif gambarnya. Sehelai kain songket berukuran mulai dari 100 centimeter x 50 centimeter dan 2 meter x 1 meter. Salah satu jenis kain songket adalah Subahnale.

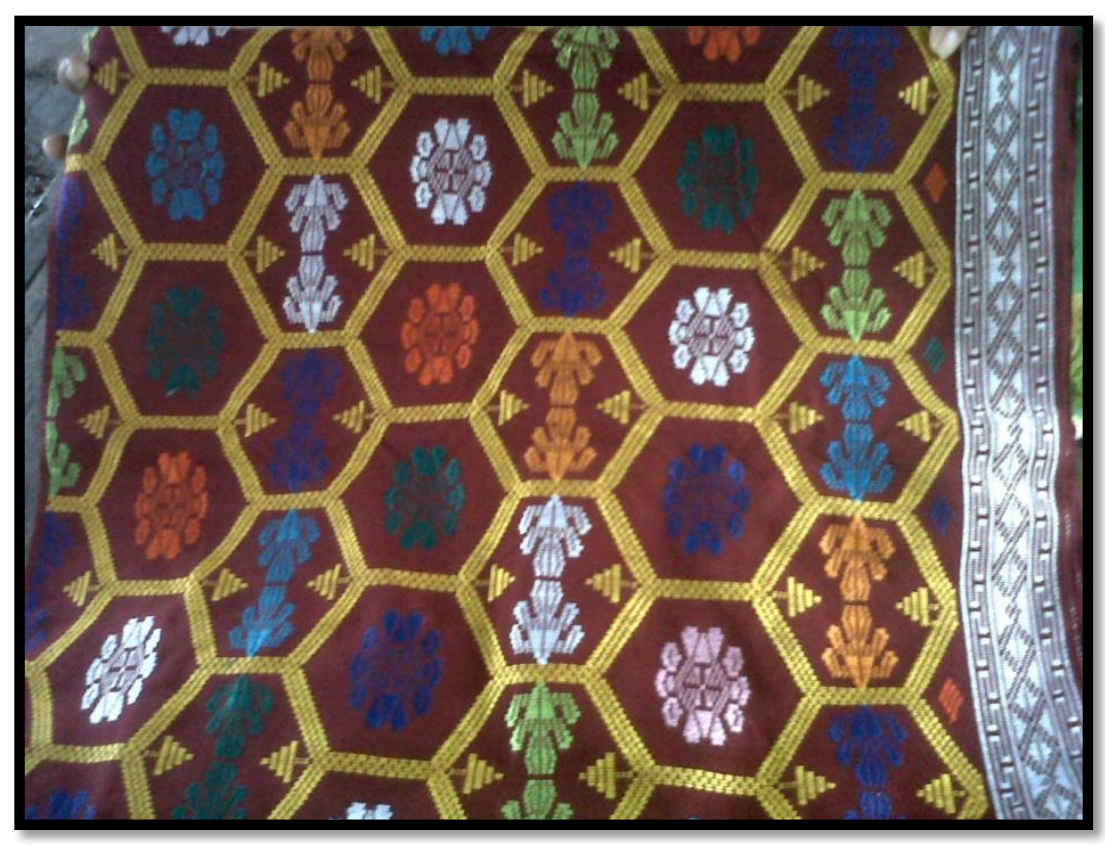

Gambar 3.1 Motif Subahnale 
Berdasarkan Gambar 3.1 ditemukan konsep-konsep matematika yaitu Segienam beraturan, Kekongruenan, Simetri lipat, Pengubinan, Perbandingan, Aljabar, dan Himpunan. Pada kain songket subahnale motifnya adalah ubinan segienam beraturan. dalam pembelajaran matematika siswa kelas IX Semester I guru dapat mengajak siswa untuk mengukur sisi-sisi dari beberapa segilima dalam kain kemudian siswa dapat menyimpulkan apa temuannya. Temuan yag diharapakan adalah siswa dapat menemukan bahwa masing-masing segilima memiliki ukuran yang sama. Dalam matematika bangun yang yang memiliki bentuk dan ukuran yang sama dikatakan Kongruen. Pada kegiatan ini siswa akan memahami konsep kekongruenan bangun datar.

Berdasarkan hasil pengukuran yang telah dilakukan guru dapat membimbing siswa untuk menemukan berapa banyak ubin segienam beraturan jika ukuran kain songket 1 meter kali 50 centimeter. Dari kegiatan tersebut siswa terlibat aktif dalam pembelajaran dengan melakukan pengukuran, mengungkapkan ide, mengungkapkan argument-argumen, dan temuan-temuan nya serta mempresentasikan temuan. Temuan yang diharapkan adalah siswa akan mengkonversi satuan meter kedalam centimeter yaitu 1 meter adalah $100 \mathrm{~cm}$ kemudian siswa membagi panjang kain songket sepanjang 100 centimeter dengan panjang sisi segilima beraturan yang telah diukur untuk menemukan banyaknya segilima sepanjang kain songket. Kemudian siswa akan menemukan berapa banyak segilima pada bagian lebar kain songket sehingga akan ditemukan banyaknya segilima pada kain songket.

Berdasarkan ilustrasi pada Gambar 3.1 dapat diketahui terdapat gambar bunga berwarna putih pada kain songket subahnale. Guru membimbing siswa untuk menemukan berapa banyaknya gambar Bunga berwarna putih jika kain songket subahnale dibuat sepanjang 5 meter dengan lebar yang sama. Berkaitan dengan pecahan maka guru dapat membimbing siswa untuk menemukan berapa bagian dari kain songket yang bergambar segilima dengan bunga putih didalamnya, dan juga dapat menemukan berapa banyak segilima bergambar Pucuk bunga berwarna putih. Selanjutnya masing-masing siswa dapat dibimbing untuk melukis motif kain songket pada kertas Karton dengan pola segilima. Siswa akan berkreasi dengan untuk mendesain motif-motif songket segilima dengan ukuran-ukuran yang berbeda-beda. Berdasarkan hasil kreasi siswa akan ditentukan karya-karya terbaik dan akan dilakukan penenunan dari desain terbaik siswa sebagai karya yang akan dipakai untuk memotivasi dan meningkatkan rasa kecintaan siswa terhadap nilai-nilai budaya tradisional khas Lombok bahkan akan meningkatkan rasa cinta tanah air (laurens, 2017) . 


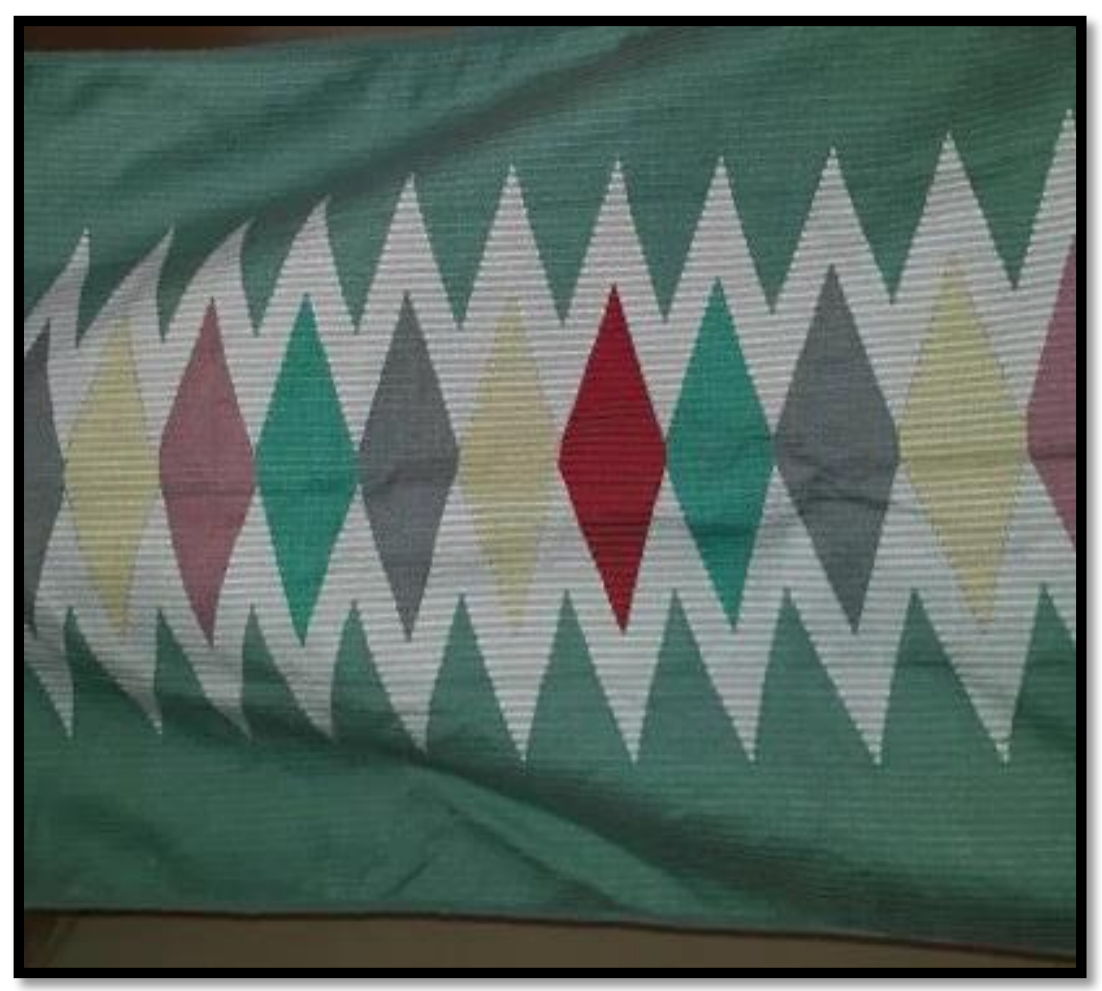

Gambar 3.2 Songket Rang-rang

Songket dengan motif Rang-rang pada Gambar 3.2 mengunakan motif geometri belah ketupat. Melalui media songket guru membimbing siswa untuk menemukan luas dan keliling belah ketupat. Aktivitas dapat diawali dengan kegiatan pengukuran sisi-sisi belah ketupat. Selanjutnya siswa dapat membandingkan luas belah ketupat besar dan belah ketupat kecil. Selain itu guru membimbing siswa untuk menemukan banyaknya belah ketupat dalam selembar kain jika ukuran kain 2 meter kali 50 centimeter.

Dengan mengajak siswa beraktifitas dalam pengukuran dan menemukan luas dan keliling secara langsung dapat meningkatkan pemahaman siswa terhadap konsepkonsep geometri khususnya konsep segitiga. Selain itu siswa dapat mengetahui matematika sangat dekat dengan segala segi kehidupan siswa. Sehingga sikap siswa terhadap matematika akan terbangun menjadi sikap yang positif. Selain membangun sikap siswa pembelajaran matematika dengan etnomatematika dapat mengurangi kecemasan siswa dalam pembelajaran matematika(Ulya \& Rahayu, 2017). 


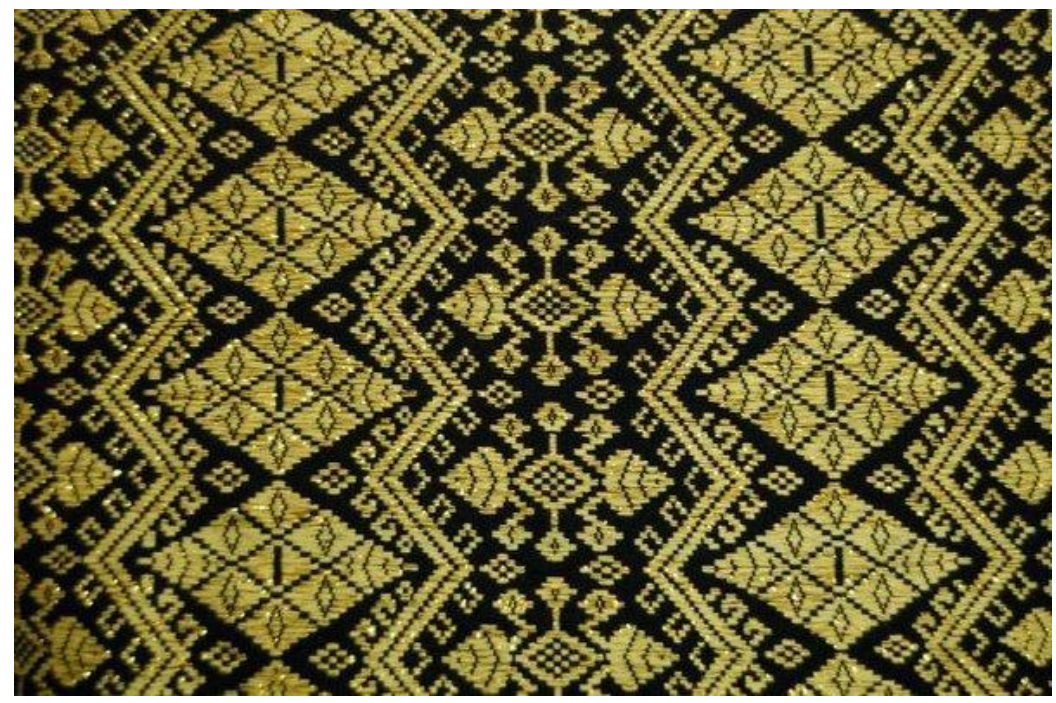

Gambar 3.3 Songket Subahnale Motif Ketupat

Kain songket subahnale motif ketupat sebagaimana diilustrasikan pada Gambar 3.3 menggunakan geometri belah ketupat sebagai motif utamanya. Berdasarkan kain songket subahnale guru dapat mengajak siswa melakukan pengukuran-pengukuran sisi dari belah ketupat kemudian menentukan sifat-sifat yang berlaku pada belah ketupat serta menentukan keliling dan luasnya. Selain itu guru juga dapat mengajak siswa untuk menentukan kekongruenan dari belah ketupat yang ada. Guru juga dapat mengajak siswa untuk menentukan simetri lipat dari belah ketupat. Guru membimbing siswa menemukan perbandingan belah ketupat besar dan belahketupat kecil yang ada dalam belah ketupat besar.

Kegiatan -kegiatan pembelajaran bernuansa etnomatematika dengan kain songket khas Lombok akan meningkatkan aktivitas siswa dibandingkan dengan siswa hanya mempelajari matematika dari buku. Siswa terlibat dalam banyak kegiatan- kegiatan pengukuran, penemuan-penemuan, penelusuran pola, bertanya, menyimpulkan dan mempresentasikan hasilnya. Siswa mendapatkan kesempatan untuk belajar dengan menerapkan media-media yang dekat dengan kehidupan siswa. Guru mengajar dengan media-media keseharian siswa. Pembelajaran yang melibatkan siswa secara aktif dan guru menggunakan media disekitar siswa adalah sangat sesuai dengan harapan dan tuntutan kurikulum K13 dalam standar proses.

Dalam proses pembelajaran bernuansa etnomatematika dengan kain songket siswa diberi kesempatan untuk belajar secara aktif (membaca, bertanya, berdiskusi, praktik, atau menggunakan media), melibatkan keterampilan berpikir tingkat tinggi, dilaksanakan melalui pengalaman yang konkret, dan menyajikan materi yang lebih 
bermakna bagi kehidupan siswa serta berdampak pada pemecahan masalah kehidupan sehari-hari.

\section{SIMPULAN}

Berdasarkan hasil penelitian maka kesimpulan dalam penelitian adalah kualitas pembelajaran matematika dapat ditingkatkan dengan menggunakan kain tradisional songket subahnale sebagai media atau alat bantu pembelajaran. Beberapa konsep matematika yang dapat dipelajari dengan songket subahnale sebagai medianya adalah kekongrueanan, kesebangunan, keliling bangun datar, luas bangun datar, simetri lipat, perbandingan, penelusuran pola. Kain songket yang dapat dijadikan media adalah kain tenun songket subahnale motif geometri seperti motif ketupat, motif rang-rang, dan segi enam. Dalam proses pembelajaran bernuansa etnomatematika dengan kain songket siswa diberi kesempatan untuk belajar secara aktif (membaca, bertanya, berdiskusi, praktik, atau menggunakan media), melibatkan keterampilan berpikir tingkat tinggi, dilaksanakan melalui pengalaman yang konkret, dan menyajikan materi yang lebih bermakna bagi kehidupan siswa serta berdampak pada pemecahan masalah kehidupan sehari-hari.

\section{REFERENSI}

Efendi, N., Sudarmawan, A., \& KetutSupir, I. (2014). Tenun Kain Songket Di Desa Sukarara, Kecamatan Jonggat, Lombok Tengah, Nusa Tenggara Barat. Jurnal Pendidikan Seni Rupa, 4(1), 1-12.

Heryan, U., \& Zamzaili, Z. (2018). Meningkatkan kemampuan Komunikasi Matematis Siswa SMA Melalui Pendekatan Pembelajaran Matematika Realistik Berbasis Etnomatematika. Jurnal Pendidikan Matematika Raflesia, 3(1), 55-66. https://ejournal.unib.ac.id/index.php/jpmr

Kencanawaty, G., \& Irawan, A. (2017). Penerapan Etnomatematika dalam Pembelajaran Matematika di Sekolah Berbasis Budaya. Ekuivalen:Pendidikan Matematika, 27(2), 169-175. http://ejournal.umpwr.ac.id/index.php/ekuivalen/article/view/3652

Khairida. (2019). Penerapan Pendekatan Pembelajaran Berbasis Etnomatematika dalam Meningkatkan Minat Belajar dan Aspek Kognitif Siswa. Jurnal Pendidikan Dan Pembelajaran Terpadu, 1(2), 114-124.

laurens, theresia. (2017). Analisis Etnomatematika Dan Penerapannya Dalam Meningkatkan Kualitas Pembelajaran. Jurnal LEMMA, 3(1), 86-96. https://doi.org/10.22202/j1.2016.v1i3.1120

Muhammad, A. F. N., \& Novitasari, N. I. (2020). Pengembangan Bahan Ajar Matematika Berbasis Etnomatematika Untuk Meningkatkan Pemahaman Matematik Siswa Kelas Iii Sekolah Dasar. Jurnal Bidang Pendidikan Dasar (JBPD), 4(1), 80-93. http://ejournal.unikama.ac.id/index.php/JBPD

Netrawati, I. G. A. O., Suastina, I. G. P. B., \& Ali, J. (2019). Hambatan Dalam Pengembangan Ekonomi Kreatif Di Kabupaten Lombok Tengah (Studi Kasus Pada 
Perajin Kain Tenun Tradisional Dusun Sade). Media Bina Ilmiah, 14(4), 2337.

Panjaitan, S., Hartoyo, A., \& Fitriawan, D. (2021). Eksplorasi Etnomatematika Kain Tenun Songket Suku Melayu Sambas. Jurnal AlphaEuclidEdu, 2(1), 19-31. https://jurnal.untan.ac.id/index.php/AlphaEuclidEdu/article/view/47890

Sarwoedi, Marinka, D. O., Febriani, P., \& Wirne, I. N. (2018). Efektifitas Etnomatematika dalam Meningkatkan Kemampuan Pemahaman Matematika Siswa. Jurnal Pendidikan Matematika Raflesia, 03(02), 171-176. https://ejournal.unib.ac.id/index.php/jpmr/article/view/7521

Suhartini, S., \& Martyanti, A. (2017). Meningkatkan Kemampuan Berpikir Kritis pada Pembelajaran Geometri Berbasis Etnomatematika. Jurnal Gantang, 2(2), 105-111. https://doi.org/10.31629/jg.v2i2.198

Ulya, H., \& Rahayu, R. (2017). Pembelajaran Etnomatematika Untuk Menurunkan Kecemasan Matematika. Jurnal Mercumatika: Jurnal Penelitian Matematika Dan Pendidikan Matematika, 2(2), 16-23. https://doi.org/10.26486/jm.v2i2.295 